Article

\title{
Sustainable Quality of Life: A Conceptualization That Integrates the Views of Inhabitants of Swiss Rural Regions
}

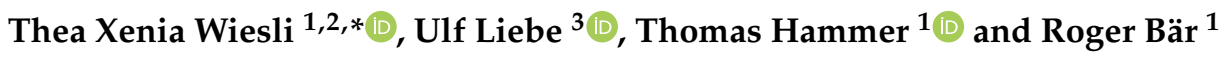 \\ 1 Centre for Development and Environment CDE, University of Bern, Mittelstrasse 43, 3012 Bern, Switzerland; \\ thomas.hammer@unibe.ch (T.H.); roger.baer@unibe.ch (R.B.) \\ 2 Institute of Sociology, University of Bern, Fabrikstrasse 8, 3012 Bern, Switzerland \\ 3 Department of Sociology, University of Warwick, Social Sciences Building, Coventry CV4 7AL, UK; \\ ulf.liebe@warwick.ac.uk \\ * Correspondence: thea.wiesli@unibe.ch
}

check for updates

Citation: Wiesli, T.X.; Liebe, U.;

Hammer, T.; Bär, R. Sustainable Quality of Life: A Conceptualization That Integrates the Views of Inhabitants of Swiss Rural Regions. Sustainability 2021, 13, 9187. https:// doi.org/10.3390/su13169187

Academic Editor: Stephen Morse

Received: 30 July 2021

Accepted: 4 August 2021

Published: 16 August 2021

Publisher's Note: MDPI stays neutral with regard to jurisdictional claims in published maps and institutional affiliations.

Copyright: (c) 2021 by the authors. Licensee MDPI, Basel, Switzerland. This article is an open access article distributed under the terms and conditions of the Creative Commons Attribution (CC BY) license (https:/ / creativecommons.org/licenses/by/ $4.0 /)$.

\begin{abstract}
In most socioeconomically wealthy countries, a high quality of life is associated with a high consumption of natural resources. It is, therefore, essential to define what constitutes sustainable quality of life-that is, quality of life that is simultaneously high as well as ecologically and socially sustainable. This issue was addressed in a study on the promotion of sustainable quality of life in rural regions of Switzerland. We interviewed 90 people with the intention of developing a concept of sustainable quality of life. The concept that emerged from our research consists of nine components: social relations and equality; nature and landscape; education and knowledge; participation, identification, and collective emotions; living; mobility; health and safety; leisure and recreation; and income and employment. Each component is formulated in an integrated way, combining social, environmental, and personal aspects. The concept provides a basis for managing regional development and promoting sustainable quality of life in rural areas. In this regard, we propose starting points in the areas of social relations and equality, nature and landscape, and education and knowledge.
\end{abstract}

Keywords: quality of life; well-being; sustainability; rural regions; regional development; Switzerland; Europe

\section{Introduction}

Among the countries of the Organisation for Economic Co-operation and Development (OECD), Switzerland offers above-average quality of life (QoL) [1]. However, Switzerland's high QoL comes with a high level of resource usage that contributes to global environmental problems. According to the Global Footprint Network, Switzerland's ecological footprint is more than four-and-a-half times as high as its biocapacity [2]. Many other wealthy countries exceed the planetary boundaries (downscaled to country level) by two to six times [3].

Recent studies have found that lower resource usage does not automatically reduce QoL [3-5]. In fact, Ambrey and Daniels found that a higher carbon footprint can even be associated with lower levels of well-being [6]. For example, a high carbon footprint can lead to negative emotions such as guilt, whereas a sustainable lifestyle can offset such feelings [6]. Furthermore, Verhofstadt et al. [5] found that a sustainable lifestyle can create win-win situations: for example, purchasing local food has positive effects on both health and environmental protection. These results suggest that reconciling high QoL with sustainability is not impossible.

The debate on how to reconcile high QoL with sustainable development began some time ago (e.g., with Boersema [7], Collados and Duane [8], or Levett [9]). Meanwhile, related concepts, such as well-being, have become important in inter- and transdisciplinary discussions on sustainable development $[10,11]$. The Sustainable Development Solutions Network and the OECD intensified the discussion on alternative measures of prosperity under the heading of well-being; they have annually published World Happiness Reports 
since 2012 [12] and the Your Better Life Index since 2011 [1]. The Your Better Life Index includes the environment as one indicator.

The Human Development Index (HDI) claims to measure and compare the development of states by measuring life expectancy, gross national income per capita, and length of education [13]. However, the HDI does not include the state of the environment or other similar indicators.

Switzerland, like other European countries, began to develop its own concept [14]. Like the Your Better Life Index, the Swiss concept contains environmental criteria in the form of a separate indicator.

The term "QoL" has often been associated with concepts such as well-being, life satisfaction, or happiness. Sometimes these terms are used synonymously. Related terms are particularly widespread in inter- and transdisciplinary expert discussions, with examples including "sustainable well-being" [15-26], "sustainable happiness" [20,27,28], and "sustainability through happiness" [29]. Costanza et al. conceptually linked an index of well-being with the UN's Sustainable Development Goals (SDGs) [10], Rogers et al. related well-being to the social aspects of sustainability [30], Bakar et al. linked economic well-being to social sustainability [16], and da Silva et al. investigated empirical ecological intensity of general well-being [31]. In contrast, sustainable QoL has rarely been used as a concept. Higgins and Campanera used the term "sustainable QoL" in empirical investigations to refer to enjoying life "without compromising future generations" [20], and Kowaltowski et al. [32] investigated links between QoL and sustainability in the context of low-income housing in Brazil.

Most of the concepts described above treat the environmental dimension and/or the social dimension of sustainability in a reductionist manner, for example, in terms of environmental quality, without including issues of justice and equality. Moreover, the environmental dimension is usually treated as a separate factor. We propose to define "Sustainable Quality of Life" (SQoL) as QoL that is linked to sustainability in all its components. Based on the United Nations' definition [33], we understand intergenerational and global justice as main aspects of sustainability. While QoL is centered in the present and focuses on the individual perspective, SQoL connects the local with the global and the present with the future. Within SQoL, we understand QoL as a holistic concept that includes subjective and objective indicators and comprises sustainability as a social and ecological as well as global and intergenerational concept.

The concept presented here results from a research project (2017-2021) in which the question of what constitutes SQoL was investigated with the overarching aim of bringing together the two concepts of "quality of life" and "sustainable development" and proposing ways of promoting SQoL in rural regions in Switzerland. Rural regions are undergoing wideranging structural and demographic change [34], which generally includes young people's migration to cities, job scarcity, population aging [35], urban sprawl, and the fragmentation of natural habitats [36]. Furthermore, rural regions have less infrastructure than urban ones; for example, they have less public transport. This poses specific challenges to rural regions, not only in Switzerland but also in other European countries [34]. The project was designed from the outset to include the views on SQoL of people living in rural areas.

The following research question guides this paper: How can QoL and sustainable development be integrated into one concept? Our aim was to provide a concept that enables regional management bodies of rural regions to promote high QoL and sustainable development at the same time. To develop this concept, we addressed the following sub-questions:

- What are the essential components of SQoL in the view of inhabitants of Swiss rural regions?

- How do inhabitants' perspectives on SQoL differ from perspectives discussed in research literature?

- What concept of SQoL results when inhabitants' perspectives are linked with perspectives compiled from the literature? 
In Section 2 (Materials and Methods), we first introduce components of SQoL derived from selected key literature, which we prepared as a theoretical background for the qualitative survey. We then describe the methodological design of the survey and 90 interviews. Section 3 (Results) presents the participants' views on what constitutes SQoL (Section 3.1), the discrepancies between their views and the preliminary components derived from the literature (Section 3.2), and the concept developed by combining participants' views with the theoretically based components (Section 3.3). In Section 4 (Discussion), we discuss the most important findings. In Section 5 (Conclusion), we propose starting points for managing regional development in a way that promotes SQoL.

\section{Materials and Methods}

Our investigation of how inhabitants of Swiss rural regions conceive of SQoL was based on a qualitative approach $[37,38]$. We developed a preliminary set of components of SQL based on key literature (Section 2.1), a guiding questionnaire (Section 2.3), and conducted interviews in four Swiss rural regions based on a theoretical sampling strategy (Section 2.2). Finally, the interviews were transcribed and evaluated using content analysis (Section 2.4).

\subsection{Preliminary Definition of Sustainable Quality of Life (SQoL)}

In preparation for the qualitative survey, we developed a preliminary definition of SQoL and its essential components based on key literature. This included philosophical concepts and empirical research underpinning the indicator systems mentioned in Section 1 [1,14]; along with seminal works on (environmental) justice [39,40], as well as "quality of life" [41] and related concepts, such as "life satisfaction" [42] and "happiness" $[43,44]$; and well-known sources used in development studies and sustainability science, such as reports published by the United Nations and secondary literature [33,45-47]. A complete list of the literature included can be found in Supplementary Information 1.

We began by defining QoL. In doing so, we excluded concepts that refer to snapshots of life (e.g., "bliss"), as our work focuses on long-term states. The term "good life" is often used in the context of German-language sustainability transformation research (e.g., Schneidewind [48]). The terms "satisfaction" and "happiness" are used often in economics (e.g., Frey and Stutzer [42], Layard [43]), and the term "eudaimonia" is employed in philosophy (e.g., Bentham and Mill [49]) and psychology (e.g., Waterman [50]). In Germanlanguage indicator systems, such as that of the Swiss Federal Statistical Office [14], the terms "welfare", "prosperity", and "well-being" are often used. "Welfare" or "prosperity" often refer to material wealth [51]. "Well-being" often describes concepts related to mental and physical health (e.g., Diener [52]). In contrast, "quality of life" mostly refers to a holistic concept with several dimensions (e.g., "The Quality of Life" by Nussbaum and Sen [41]). For this reason, we chose QoL as the underlying concept for our approach. "Objective data", such as life expectancy or income, make it possible to assess the external conditions in which a population lives, and to compare these among different populations [15]. "Subjective data" based on people's self-assessment of their satisfaction make it possible to integrate their perspectives and emotions. Following Costanza et al., we define QoL as consisting of both subjective and objective aspects [15].

The definition of "sustainability" that we chose is based on the UN's "Brundtland definition" and their 2030 Agenda with its SDGs. Accordingly, "sustainability" in our preliminary definition of SQoL means that all people should be able to live a good life, both now and in the future [45-47]. Due to this distribution-oriented, global, and intergenerational understanding of sustainability, we consider justice to be an essential link between QoL and sustainability, and thus a condition for SQoL. A sustainability concept consisting exclusively of the three-pillar model—with the pillars representing the social, economic, and environmental dimensions of sustainability [53]—offers little differentiation and is strongly reduced in complexity. The so-called "Brundtland definition" goes further by including global and intergenerational justice; it defines sustainability as including judicious use of resources, protection of nature, the satisfaction of basic needs, and poverty 
eradication [47]. The 2030 Agenda and its SDGs extend the focus from developing countries to include industrialized countries as well, and the 169 targets connect ecology and economics to disparity and human rights [33]. We refer to this most recent UN understanding of intra- and intergenerational sustainability, as it lays the foundations for placing a collective, distribution-oriented claim on high QoL.

To address ecologically and socially problematic areas of life that commonly contribute to the QoL of individuals, we selected literature with a focus on individuals' ecological footprint, as well as on environmental and social justice $[39,40,54,55]$. We chose Rawls's theory-(one of) the most influential theories of justice published in the 20th century that has also been critically discussed - to define justice for SQoL. Approaches such as liberalism (e.g., Hayek [56], Nozick [57]), which focus on maximum individual freedom, seemed less appropriate in the context of an intergenerational and global understanding of sustainability. On the other hand, utilitarian approaches (e.g., Mill [58], Bentham [49]), in which justice is sought through the greatest benefit for all and the maximization of happiness, seemed too generalized for our purpose. Rawls's theory is convincing because it does not reduce justice to universalistic claims or an aggregation of utility. His theory offers an in-depth understanding of the spatial and temporal dimensions of sustainability that is highly useful in defining SQoL, and makes it possible to combine the particular (individual claims) with the universal (pluralistic claims). Firstly, it states that one generation's behavior should not diminish another generation's options [39]. Therefore, any orientation towards the greatest benefit for a society should include future generations [39]. Secondly, Rawls's definition of justice includes the inherent principle of difference. This principle states that people start from different, more or less advantageous positions. Justice, in this context, means arranging social and economic inequalities in a way that they are "to the greatest benefit of the least advantaged" [39]. This focus on the least advantaged members of society can imply an unequal distribution of resources if legitimate [45].

The selected literature suggests that SQoL consists of several components. We compiled these by combining elements of QoL and sustainability derived from the selected literature. We purposely formulated the components in an integrated way, with sustainability forming an integral part of all components rather than a separate dimension. An overview of the components, including a description and justification of targets, and the respective literature sources is provided in Supplementary Information 1.

The first component we defined was social relations and equality, drawing on Schlosberg [40] and Nussbaum [59], among others. In addition to the definition of justice based on Rawls, we derived equality from the principle of difference described above and from Schlosberg's concept of recognition [40]. According to Schlosberg, the recognition of other groups and different concerns is essential in designing consensual sustainable development strategies and in achieving distributive justice [40]. The partial component of social relations mainly refers to Nussbaum's "list of capabilities" [59]. The ability to bond with people, form friendships, and engage in social interactions are integral elements of Nussbaum's list of capabilities, and thus of QoL [59]. Derived from these key sources, the component social relations and equality comprises the target of freedom and equal opportunities for social relations, recognition, and no discrimination within SQoL.

Based on Schlosberg's definition of justice [40] and on Nussbaum's list of capabilities [59], we included participation and identification as a second component of SQoL. The criterion of participation is in line with Schlosberg's definition of "environmental justice" [40]. Based on the capability approach of Sen and Nussbaum, Schlosberg shows that environmental justice is not only concerned with the distribution of resources, but also with the ability to use and apply them [40]. Furthermore, the capability approach implies that opportunities and self-determination are important preconditions for a successful life [59]. A successful life includes the freedom of action and decision needed to shape one's life independently [59]. Drawing on Fraser and Young's concepts of justice, Schlosberg argues that "procedural justice" should ensure that all individuals can participate in political and economic processes [40]. The partial component of identity in our definition of SQoL is in 
line with Nurse, among others, who argues that cultural identity is an essential element of sustainable development because identities shape systems of meaning and views of the environment and development [60]. In summary, participation and identification as a component of our definition of SQoL is achieved if the individual enjoys freedom of choice, has the right to have a say, participates effectively in social processes, and identifies with their social environment and home area.

Drawing on Nussbaum's arguments, we added nature and landscape as a third component of SQoL. Nussbaum's list of capabilities [40] contains affection for nature and other species. Referring to this capability, Schlosberg argues for an understanding of justice that is not purely anthropocentric but extends to other species, such as animals [40]. Likewise, we considered what Nussbaum describes as "being able to have attachment to things and people outside ourselves" [59] to be an obvious prerequisite for sustainable development. It is an important way of regarding nature and its resources, and it is required in order for an individual to be able to distribute them fairly. Research shows that nature and landscape are essential to mental and physical health. They are important for identity creation, positive emotions, and awareness of sustainable development [61-67]. Accordingly, the component of nature and landscape added to SQoL the target of a high quality of nature and landscapes for all present and future generations.

Further, we included education and knowledge as well as health and safety as fourth and fifth components of SQoL. They are likewise derived from Nussbaum's list of capabilities [59]. According to Sen's and Nussbaum's capability approach, good education and knowledge are essential for an individual-for their development, for shaping their own life, and for participating in social life $[59,68]$. The target for this component within SQoL is a good education and knowledge on general and specific topics as well as on sustainability. This comprises the ability to absorb and process information, think critically, and use personal knowledge.

Another capability in Nussbaum's list is bodily integrity, which enables the physical and mental constitution necessary to have a successful life [59]. The target for the component health and safety in our preliminary definition of SQoL is thus a long and healthy life without fear and without the danger of conflicts or negative environmental and climatic influences.

Leisure and recreation as well as income and employment were added as the sixth and seventh components of SQoL. These components, or parts thereof, are included in many indicator systems [1,14,33] and in the above-mentioned empirical studies of satisfaction [42-44]. For example, the "Your Better Life Index" of the OECD and the "Well-being indicators" of Switzerland's Federal Statistical Office, among others, contain the indicator "work-life balance" [1,14]. "Work-life balance" in the "Your Better Life Index" is justified by the importance of general well-being, family life, and the possibility to reconcile professional and private commitments [1]. The Federal Statistical Office also justifies the inclusion of work-life balance with gender equality, since it should increase women's career opportunities [14]. We included work-life balance in SQoL as part of the component income and employment. This component included the target of employment that is freely chosen, meaningful, and provides sufficient income and a good work-life balance within the framework of a resource-efficient and environmentally friendly economy [33].

The fact that leisure activities are needed for expression and social life [59] justifies the component leisure and recreation. Furthermore, according to Kurt and Wagner [69], culture as part of sustainable development enables dialogue among diverse individuals and groups, as well as openness, creativity, and changeability of areas such as economy and ecology. We defined the target of this component as including leisure activities, recreation, and cultural activities that are as environmentally friendly as possible and compatible with the conservation of renewable natural resources.

The eighth component we included in SQoL is living. According to Preisendörfer [55] or the Federal Statistical Office [14], among others, we defined living conditions appropriate to the individual situation and free of environmental pollution as essential to well-being 
and sustainability. Accordingly, the target of the component living is to have appropriate, environmentally friendly, and resource-efficient living conditions.

Finally, we included mobility as the ninth component of SQoL. Based on the Federal Statistical Office's [14] and Nussbaums' arguments [59], we consider mobility to be fundamental for the supply of goods and services and for the resulting individual freedom as a capability $[14,59]$. Based on Meschik and Meth's [70] work on pro-environmental mobility behavior and the Federal Statistical Office's indicator system [14], we defined the target of the component mobility as resource-efficient and accessible mobility for everyone.

According to the Global Footprint Network's national footprint calculations, mobility, energy, and agriculture have the greatest impact on the national footprint in most countries [54]. We included energy in SQoL mainly in the mobility and living components; agriculture is included via nutrition in the health and safety component. Mobility and energy may also be included indirectly in other components of SQoL. For example, mobility might be necessary to visit friends and family (social relations and equity component) or to reach the workplace (income and employment).

Overall, this preliminary definition of SQoL consists of nine components that are referred to by different terms in the literature. Compared with other concepts discussed in the literature that focus on QoL or environmental aspects, our preliminary definition of SQoL links QoL and sustainability within each component.

\subsection{Study Areas and Sampling}

We decided to conduct interviews in four regions in order to cover a variety of rural regions. Since we intended to include representative and comparable municipalities in the four areas, we selected them accordingly based on the typology of municipalities published by the Swiss Federal Statistical Office [71]. All four regions are relatively densely populated compared to the alpine regions; for example, the Aargauer Jura has 168 inhabitants per square kilometer. This makes them typical of a large part of Switzerland [14].

To ensure that our survey would include a diversity of perspectives within each region, we planned to conduct at least 20 interviews per region. In total, we conducted 90 interviews in the four regions, namely 22 interviews each in the Freiamt and Entlebuch regions and 23 interviews each in the Gantrisch and Aargauer Jura regions. Our sampling strategy followed the theoretical sampling method of Glaser and Strauss [72]. This allowed us to adjust the sampling to the sociodemographic situation of the villages and to include participants with diverse backgrounds. We explicitly avoided snowball sampling in order to minimize sociodemographic biases. Participants were recruited in public places, in consideration of the sampling targets. This approach resulted in the sample presented in Table 1 . The 90 interviews provided sufficient material and qualitative insights alongside satisfactory variance across sociodemographic groups. Although we did not aim for a representative quantitative study, this sample of 90 participants is large enough to cover the views of a wide variety of groups among the rural population. 
Table 1. Sample of interview participants.

\begin{tabular}{lll}
\hline Sociodemographic Factors & $n$ & $\%$ \\
\hline Sex & 44 & 48.8 \\
Male & 46 & 51.1 \\
Female & $\mathbf{9 0}$ & \\
Total & & \\
\hline Occupation & 13 & 14.4 \\
Forestry/agriculture & 9 & 10.0 \\
Trade/industry & 36 & 40.0 \\
Services & 15 & 16.6 \\
Undergoing education & 1 & 1.1 \\
Unemployed & 16 & 17.7 \\
Retired & $\mathbf{9 0}$ & \\
Total & & \\
\hline Education & 11 & 12.2 \\
Lower secondary education & 61 & 67.7 \\
Upper secondary education & 18 & 20.0 \\
Tertiary degree & $\mathbf{9 0}$ & \\
Total & & \\
\hline Age & 26 & 28.8 \\
16-29 years & 38 & 42.2 \\
$30-59$ years & 26 & 28.8 \\
$\geq 60$ years & $\mathbf{9 0}$ & \\
Total & & \\
\hline N =90. & & \\
\hline
\end{tabular}

$\mathrm{N}=90$.

\subsection{Qualitative Interviews}

We used a semi-structured interview guide based on the components of SQoL introduced in Section 2.1. The guide was ordered flexibly and followed the conversational flow (see guide in Supplementary Information 2). Before conducting the interviews, we tested and refined the questionnaire in several iterations. Then, the first author and an assistant conducted the interviews. Both interviewers carefully avoided suggestive questions and elicited opinions, feelings, or justifications in an open way by asking, for example, "Why do you think so?" or "How do you feel about this?". The interviews took $50 \mathrm{~min}$ on average.

The first part of the interview included open questions about what SQoL is in the participant's view, and what concrete components constitute SQoL. Thereafter, the interviewers asked the participants about their opinions on the components derived from the literature.

The second part of the interview focused on the idea of linking QoL with sustainability, and on the feasibility of doing this. The interviewers explained our definition of sustainability and asked the participants for their general opinion on sustainability and on the link to QoL. The participants were then asked about their opinion on our preliminary set of components of SQoL-this time with our definition of sustainability (described in Section 2.1) in mind. This procedure made it possible to approach the topic of sustainability openly in the first part of each interview, and in the context of the UN's understanding of sustainability in the second part.

\subsection{Transcription and Content Analysis}

The interviews were transcribed verbatim in Swiss German using the content analysis method described by Breuer et al. [73] and Dresing and Pehl [74] (see transcription guide in Supplementary Information 3). Text passages that deviated greatly from the subject of the research question were only summarized [73].

The subsequent content analysis allowed us to organize the transcribed data and its content systematically. We followed the method proposed by Mayring [75] and used MAXQDA, a software for computer-assisted qualitative data and text analysis. 
First, we formulated deductive categories based on the components of SQoL as described in Section 2.1. Subsequently, the first author and the assistant began coding (see guide for content analysis in Supplementary Information 4). After coding the interviews using the deductive categories, they recoded them in an iterative process, formulating new inductive categories and subcodes based on the context of the interviews (see codebook in Supplementary Information 5). A precise description of the coding rules, anchor examples, and justifications were added in a code memo for each newly created code to create a mutual understanding of how the code should be employed (see code memos in Supplementary Information 5). The first interviews were coded by both researchers, and whenever they disagreed, the interviews and codes were discussed in detail to achieve consensus. The first five documents coded in this way showed that the researchers had a very similar coding style. They then no longer coded the same interviews in parallel, but still frequently consulted each other. Once the first $40 \%$ of the interviews had been coded, the content no longer required any new codes. While coding, the two coders routinely recorded their thoughts and initial interpretations in text memos. Once all interviews had been coded, certain codes that might have been used discontinuously were checked again and recoded as needed. Finally, the researchers read over each other's coded data and supplemented the coding whenever necessary.

For the final interpretation, the subcodes were regrouped into broader categories where appropriate, and were compared to the components of our preliminary definition of SQoL. Finally, we merged the empirical results with the preliminary definition by adding to the latter the subcomponents and respective justifications emerging from the interviews. This resulted in our final concept of SQoL.

\section{Results}

In Section 3.1, we present the interview participants' views of SQoL and its components. In Section 3.2, we describe the main discrepancies between the interview participants' views and our preliminary definition. Finally, in Section 3.3, we present the SQoL concept that results from merging the empirical results with the preliminary definition.

\subsection{The Interview Participants' Views on SQoL}

Across all interviews, about two thirds of the respondents said spontaneously that family, friends, and the natural environment surrounding them were most important to them. These statements concern the two components social relationships (and equality) and nature and landscape. For example, one respondent stated:

"Family, my parents, my siblings - if there is anything you need help with, you know where you can go. This is probably a basic trust, and it is clearly quality of life for me. That I somehow know that this will always be dependable. And then to be here in nature also provides a quality of life that might be a little less available in the city and which is certainly one reason why we are here." (IP 44, female, 30-59 years, services, completed upper secondary education)

The participants stated that relationships with family and friends give them a sense of consistency. In addition, around one third of the participants mentioned loyalty within the village neighborhood as being important to them. We included this as a further part of the social relations and equality component. Across all respondents, the interviews confirm the basic human need for social relations.

The importance of nature and landscape was revealed to be associated with social relationships. Nature and landscape were often described as locations for sports like hiking, cycling, and skiing, and as a place to visit with family and friends. The participants thus described social relationships as part of their leisure and recreation. In addition, leisure and recreation was described as an enabling factor in forming relationships. In addition, participants mentioned proximity to nature as a criterion for choosing their place of residence. 
The remaining (sub)components that we had prepared for the interviews were mentioned far less frequently by the interview participants. However, when the researchers asked about them, most participants agreed to counting these components as part of SQoL.

The following example illustrates how certain components-in this case safety (as part of health and safety) - were considered important, but were usually not present in the participants' minds because they more or less take them for granted:

"Safety is certainly very important for life. But it is a bit more abstract in Switzerland, because the issue isn't pressing, at least not for me. At least not concerning physical, legal, or financial safety, or that I will find a job later. In these regards, I feel safe. But it is important." (IP 94, male, 16-29 years, agriculture, tertiary degree)

A good state of health was considered to be a fundamental basis for QoL. People in the age groups above 30 described health as something transient that should be valued. Some participants explained that the health component was only considered important when an illness occurred. As one respondent stated:

"Health is very valuable, but you wouldn't think of it as long you are healthy. Only if you or somebody else in your family is ill, do you become aware of it. But we should appreciate it more when we are healthy." (IP 71, male, over 60 years, retired, completed secondary school)

In addition, participants also mentioned regionally sourced food as a benefit of rural life. The possibility of buying directly from farmers is seen as sustainable and as an indicator of QoL.

The living component was mostly associated with the possibility of having one's own garden, and with the landscape and nature in the surrounding area. Both were often described as important criteria for living in rural areas. It can be assumed that this requires an unspoiled environment. Another criterion that influenced many participants' decision to move to a village was the possibility of buying their own home. Some owners of a house mentioned having photovoltaic cells.

Although participants rarely addressed the participation (and identification) component on their own, they strongly agreed when asked whether this was part of SQoL. Many of them explained that direct democracy with votes on substantive issues is important, even if they do not always make use of their right to vote. At work, they consider it important to contribute their ideas and opinions. Participants in the young age group (16-29 years) often mentioned that they lack this opportunity. Participants also considered participation important in the context of being able to make independent decisions within a partnership. These considerations are in line with the description in our preliminary definition. One respondent stated:

"Very important, I indeed have something to say (laughs). And it is also important to me that we move ahead together, be it because you are in an association, I am in the women's sports club, and there, too, I think it is important that one is asked or that one can contribute ideas. And particularly in our business, of course, which my husband and I lead and direct together." (IP 08, 30-59 years, female, agriculture, completed upper secondary education)

Self-determination, as part of the component participation and identification, was also stressed as being very important by participants when asked. The term was used in relation to several areas of life, and self-determination was considered particularly important with regard to work, hobbies, family life, and one's role as a woman. The young age group (16-29 years) often raised the subject on their own initiative and emphasized their desire for independence from authorities. As one respondent stated:

"I would not want to live in a place where others would decide for me. I think this would reduce the quality of life for me personally and certainly also for many others. At work there is of course a certain reality that you can't determine everything yourself, and that's okay. But 
even there, simply to choose a job and not be forced to do one, this means a lot." (IP 82, male, 16-29 years, undergoing education, completed upper secondary education)

When asked, the participants agreed that they could clearly identify with their home area, and they mentioned this as important for a good life. Another 13 participants said of themselves that their sense of (participation and) identification was based more on their social relationships than their area. Another five participants identified strongly with the surrounding nature and landscape. One respondent said:

"But being rooted in the village... Rather in the surroundings, in nature here. I regularly go running, you can put on your shoes and go running across the fen. That's what I mean." (IP 23, female, 30-59 years, services, tertiary degree)

When questioned on the education and knowledge component, participants agreed that education and knowledge is important. Some stated that education on the environment and sustainability should also include ecological behavior in everyday life. These participants described everyday situations in which they sometimes did not know for sure which behavior would be less resource-intensive.

The income and employment component was confirmed to be important when we asked participants about it. Participants who had chosen a reduced workload said it was significant for QoL and the associated reduction in income and consumption was not very relevant to them. As one respondent stated:

"I don't think I could ever work 100 percent. [...] We've reached a point in Switzerland where many people no longer have to work to survive, and I think it's a pity if we don't make use of this privilege to do what we want or find another purpose in life than getting a lot of money and a house." (IP 94, male, 16-29 years, agriculture, tertiary degree)

Participants' opinions about work-life balance and meaningful employment are consistent with the literature. Moreover, income was indeed referred to as a relatively important component of SQoL. However, the participants often compared income to components like health, which they considered to be more important for QoL.

The interview participants also mentioned elements that we had not included in our preliminary definition of SQoL. Nine participants mentioned emotions, such as calmness as a common mood, or familiarity as a typical characteristic of rural life and a very important part of SQoL in their view. According to the descriptions in the interviews, such emotions form in a collective, arise from shared attitudes, can result in trust and freedom, and represent the mood of an entire society. The participants often contrasted the common calmness with city life, which they perceive as hectic and characterized by pressure to perform. One respondent stated:

"I don't know whether I could live in the city, because I'm not used to it. And I think it's quite nice actually, just quiet, coming home, no stress and no hectic." (IP 90, female, 16-29 years, undergoing education, completed upper secondary education)

Twenty-three participants mentioned membership in associations as an essential part of their QoL. Being a member of an association or club is particularly relevant with regard to social relationships, loyalty, communication, and networking. Moreover, it can facilitate the integration of newly arrived inhabitants.

As many as 36 participants mentioned the importance of efficient and frequent access to cities by public transport. Many of them justified the importance attached to ease of mobility with reference to reaching a meaningful workplace or a wider choice of cultural and leisure activities. Furthermore, participants often explained that they had chosen their place of residence based on the train connections to larger cities.

Based on these findings, it can be stated that the interview participants considered all nine components in our preliminary definition to be essential for SQoL. Moreover, they did not mention any completely new components in addition to the ones we had included in the preliminary definition. (We cannot fully rule out the possibility that respondents might have agreed with further components if they had been mentioned by 
the interviewers.) However, within the nine components in our preliminary definition, the interviews revealed new and important justifications and aspects: (1) the feeling of calmness, (2) membership in associations, and (3) access to cities. Furthermore, the interview results indicate interrelations between the different components. In particular, nature and landscape is connected to health and safety; to social relationships and equality; to living; and to leisure and recreation.

\subsection{Discrepancies between Inhabitants' and Theoretical Perspectives on SQoL}

Comparison of the empirically collected views with our preliminary definition (see Section 2.1) reveals a number of discrepancies between the two. Overall, most interview participants considered QoL that is both high and sustainable-as described in our preliminary definition of SQoL-to be difficult to achieve and unrealistic. While participants regarded their QoL as very high, they perceived sustainability as an acute challenge. As one respondent put it:

"We no longer need to improve our quality of life. Of course, we have to look after the environment. See that people have good cars, that they cycle more, or travel by train. I think such things are okay. But quality of life, that we should be even better off-we are far too well off as it is." (IP 73, male, 30-59 years, services, tertiary degree)

Of all the components, equality (as part of social relations and equality) proved to show the greatest discrepancies between the participants' descriptions and our description based on the literature. Firstly, when asked, participants described gender equality as being highly desirable, but not fully achieved at present. Thirteen participants-more women than men-clearly agreed that gender equality is important, and showed a critical attitude. As one participant stated:

Somehow gender equality hasn't arrived here yet. We're a bit slower here. (IP 04, female, 16-29, undergoing education, completed upper secondary education)

A few young male participants described the topic as obsolete, whereas people in the medium and older age groups said that gender equality remained insufficient. Their criticisms related to lower incomes and fewer opportunities for women in professional life and politics.

Secondly, some participants $(n=3)$ criticized the low acceptance of homosexuality. They also disapproved of the legal complexity of same-sex parenthood.

Thirdly, 29 participants clearly agreed that the topic of accessibility to people with disabilities was important to them. Other participants did not see this as a priority because it affects only a minority. Some participants criticized the fact that there was still a lack of barrier-free apartments for rent, or they mentioned examples of insufficient accessibility experienced in civic engagement.

Fourthly, equality among people of different nationalities seems to be less socially desirable for participants. They do not necessarily see such equality as unconditional or self-evident. Most participants associated equality among people of different nationalities with migration. As many as 27 participants clearly disagreed with equality between natives and different immigrant groups in Switzerland. Of these participants, 12 expressed a nationalistic attitude, and the well-being of Swiss people was clearly the foremost priority in their minds. Some of them described their fears of migrants or expressed their disparagement of other ethnic groups. One respondent stated:

"Basically, I think that we need to look after Swiss people first. And if things go well for us here, you can still look after those from abroad, because that's exactly what I think the idea of the nation state is [...]. Refugee policy should also be approached more restrictively [...]." (IP 15, male, 16-29 years, undergoing education, completed upper secondary education)

Meanwhile, another group-13 of the 90 participants-replied that they do not perceive equality between people of different nationalities, and that the villagers are not open to newcomers. 
A certain discrepancy between the descriptions of the participants and our preliminary definition of SQoL also emerged in the mobility component. The majority of participants $(n=79)$ agreed that mobility - and in particular sustainable mobility-is important. Public transport in general was described as an environmental benefit and as beneficial for elderly people as well as for everybody without a driving license. The participants emphasized the high quality of train transport in Switzerland. Nevertheless, most of them said that they themselves drive a car, and the car was the most important means of mobility in their area. Accordingly, participants' perceptions and their main mobility settings were not in line with the idea of sustainable mobility.

A discrepancy also emerged with regard to renewable energies within the component living: Tenants complained that they cannot choose renewable energy in the municipality they live. As one interview participant stated:

My neighbor installed these photovoltaic panels on his roof. But that's no use to me and I'm not allowed to do that because I don't own the house. (IP 11, female, 30-59 years, housewife, completed compulsory school)

In summary, participants' descriptions of the current situation related to equality, mobility, and living differ to some degree from the theoretical views compiled in our preliminary definition of SQoL. This points to challenges in the investigated rural regions. Furthermore, some interview participants' perceptions of equality are not in line with the theory underpinning our preliminary definition of SQoL, which can be viewed as another challenge facing the investigated rural regions.

\subsection{An Integrated Concept of SQoL}

This subsection presents our concept of SQoL that resulted from merging our empirical results with the preliminary definition. Table 2 lists the components of SQoL, ordered by the number of participants that regarded them as clearly important.

Four additional sub- and partial components are added to our preliminary set of components: collective emotions, membership in associations, part-time employment, and access to cities. According to participants, mobility is fundamental for accessing employment, education, and cultural activities. We therefore integrated sustainable access to cities as part of the target and justification of the component mobility (see Table 2).

We named the emotions of calmness and familiarity "collective emotions" and added this as a partial component to participation and identification. According to the interviews, these emotions are related to, or partly dependent on, participation and identification. For example, several interview participants mentioned membership in associations as enabling social and intercultural participation. Therefore, we integrated this as a justification of the component participation, identification, and collective emotions. 
Table 2. Components of Sustainable Quality of Life (SQoL). Justifications and targets emerging from the interviews are set in bold script.

\begin{tabular}{|c|c|c|}
\hline Component & Target & Justification \\
\hline $\begin{array}{l}\text { Social relations } \\
\text { and equality }\end{array}$ & $\begin{array}{l}\text { The greatest possible freedom and equal } \\
\text { opportunities. Intra- and } \\
\text { intergenerational justice. Opportunities } \\
\text { for social relations. No discrimination } \\
\text { based on gender, ethnicity, religion, } \\
\text { species, or other affiliation. Recognition } \\
\text { of potentially excluded groups as a basis } \\
\text { for (environmental) justice. }\end{array}$ & $\begin{array}{l}\text { Justice and recognition are fundamental to living a } \\
\text { self-determined life with equal opportunities, in freedom, } \\
\text { without environmental pressures, and with sufficient resources. } \\
\text { Living in a society, having relationships, and thus feeling } \\
\text { empathy for other people and other living beings satisfies the } \\
\text { human need for closeness and enables joint development. }\end{array}$ \\
\hline $\begin{array}{l}\text { Nature and } \\
\text { landscape }\end{array}$ & $\begin{array}{l}\text { High quality of nature and landscapes for } \\
\text { all present and future generations. }\end{array}$ & $\begin{array}{l}\text { High-quality nature and landscapes stimulate positive emotions } \\
\text { and have a positive influence on physical and mental health. } \\
\text { Nature and landscape enable recreation and community } \\
\text { experiences outdoors. }\end{array}$ \\
\hline
\end{tabular}

\section{Education and} knowledge

\section{A good general and specific education} and knowledge. Education on the environment and sustainability. The ability to absorb and process information, think critically, and use one's personal knowledge.

Appropriate, environmentally friendly, and resource-efficient living conditions

Living that are not impaired by environmental pollution.

Participation, identification, emotions

Freedom of choice, the right to have a say, and effective participation in social processes. Identification with one's social environment and home area and a positive collective mood. and collective

A good education and knowledge is essential to individual development, to shaping one's own life, and to participating in social life. Education on the environment and sustainability enables people to increase sustainability in their own lives and to contribute to development.

Living conditions appropriate to the individual situation that are not impaired by environmental pollution are essential to well-being. To reduce environmental pollution, it is important that living should be as environmentally friendly and resource-efficient as possible for everyone.

Participation and freedom of choice are important for self-determination and the control over one's personal well-being. Identification promotes participation in social processes and reduces the likelihood of conflict. Positive collective emotions are essential for mental well-being as well as for trust and freedom in a society. Membership in associations enables social and intercultural networking and integration.

Environmentally friendly and resource-efficient mobility for everyone, including efficient and frequent access to cities.

Mobility is fundamental for the supply of goods and services, for accessing appropriate employment and education, for cultural activities, for individual freedom, and for the maintenance of social relationships.

A long and healthy life without fear and without the danger of conflicts or negative environmental and climatic

Health and safety influences. Availability to all individuals of fresh and locally produced food, without overuse of resources.

Leisure activities, recreation, and cultural activities that are as environmentally

Leisure and recreation friendly as possible and compatible with the conservation of renewable natural resources.

Employment within a resource-efficient and environmentally friendly economy.

Income and Employment that is freely chosen, employment
A good physical and mental individual constitution, safety, and an intact environment are essential conditions for a successful life. Fresh food is essential for health and enjoyment. Local, ecological production and moderate consumption enable a fair distribution of food while keeping nature intact.

Leisure activities, recreation, and cultural activities satisfy the need for expression, social life, entertainment, and education. Culture and art offer opportunities for sharing, creativity, and an understanding of common values that can promote sustainable development.

Sufficient income and meaningful work are essential for a successful life. Sufficient time, and hence part-time employment, can benefit the environment and increases personal satisfaction. To counteract scarcity of natural resources and existing environmental and social problems, it is important that income and work are generated within a resource-efficient and environmentally friendly economy that ensures fair distribution. meaningful, and provides sufficient income, a good work-life balance, and the option of working part-time. 
According to the participants, working part-time can benefit the environment while increasing personal satisfaction. Consequently, we included participants' arguments for an appropriate workload under income and employment.

Finally, the participants considered locally and ecologically produced food to be important for their health. Accordingly, we included sustainable and healthy food in the target and justification of the health and safety component.

The concept proposed in Table 2 contains nine components that all constitute SQoL in the view of the interview participants. Furthermore, in addition to the justifications and targets compiled from the literature, it includes additional targets mentioned by the interview participants.

\section{Discussion}

This study resulted in a concept of SQoL consisting of nine components with specific targets and justifications: social relations and equality; nature and landscape; education and knowledge; participation, identification, and collective emotions; living; mobility; health and safety; leisure and recreation; and income and employment. Our results showed that developing a concept of SQoL requires a comprehensive, broader approach than similar concepts that focus more narrowly on aspects like basic needs (e.g., Kowaltowski et al. [32]), healthrelated well-being (e.g., Abraham et al. [61]), or climate or carbon emission indicators (e.g Verhofstadt et al. [5]). SQoL integrates social and ecological sustainability in all its components. This sets it apart from concepts that treat ecological factors as a separate dimension (e.g., Federal Statistical Office [17] and others [1,3,25,76])

The interviews revealed important justifications and relationships between components of SQoL: social relations and nature and landscape emerged as the components that interview participants considered most important, and connections were frequently established between them. Income and employment as well as education and knowledge were perceived as enabling other components of SQoL, such as leisure and recreation or living.

Social relationships and equality as well as nature and landscape, in contrast, seem to be experienced as beneficial in themselves. The views of the interview participants on nature and landscape underline arguments in the literature: nature and landscape enable recreation and community experiences outdoors and, therefore, have a positive effect on mental and physical health $[61,77,78]$. The discussion on "place attachment" in literature also links nature and landscape with identity, for instance based on its function of mental stabilization [64]. According to Nussbaum, landscapes can evoke feelings of identification, and social relations can generate empathy for a region [79].

The collective emotions and the importance of being a member of associations revealed in the interviews provide further related insights on SQoL. According to Nussbaums' theory in "Political Emotions", emotions are a prerequisite for a successful life and are rational and essential parameters for decisions [79]. Loyalty, as well as shared positive emotions, are therefore important for politics and society in that they make it possible to achieve common goals [79]. In the present context, sustainable development represents such a goal. Furthermore, collective action can, according to Ostrom, overcome the central problem of commons overuse ("the tragedy of the commons" [80]) by enabling joint organization and coordination of resource use. Collective emotions and membership in associations as part of SQoL can thus be interpreted as levers for establishing common governance of resource use in a sense similar to Ostroms' "governing the commons" [80].

The mention of part-time employment by the interview participants revealed another important perspective on SQoL. Some of the respondents seemed to prefer more time to higher income. Accordingly, consumption seems less important to these individuals than leisure time. Based on this, we see part-time employment not only as beneficial to individuals' QoL but also as likely to benefit the environment. Empirical studies confirm that in many high-income OECD countries, working hours and the associated consumption have an impact on the per capita ecological footprint [81]. 
However, our study also showed that a considerable proportion of people in the investigated rural regions in Switzerland identify the overall idea of linking QoL with sustainability as a major challenge. This confirms findings from the literature: while QoL goals have already been achieved in Switzerland [1,3], the integration of sustainability remains problematic $[82,83]$. Furthermore, the results show that topics concerning equality are challenging. Another major challenge is mobility; this, too, has been shown in previous studies on mobility in rural regions [84].

An important question is how representative the results of this study are. The transferability of our results to urban areas is likely to be limited, as the importance of some components of SQoL might differ between contexts. Concepts such as QoL and well-being are typically seen as context-specific [30]. Sociodemographic characteristics, the natural environment, and infrastructure might influence people's perceptions of SQoL. For example, the need for travelling by car is smaller in most cities than in rural areas [85]. This may shape opinions on mobility. Above all, nature and landscape, identification (with one's home area), collective emotions, and membership in associations may have a different meaning for villagers than for city dwellers. In cities, social proximity, which our interviewed inhabitants of rural regions view as positive, might also be perceived as social control. Developing a concept of SQoL in urban areas could thus be an interesting field for further investigations.

Since our sample included four rural regions that each included several types of municipalities and diverse sociodemographic groups, it can be assumed that the results of our study can be transferred to other rural regions in Switzerland and to comparable rural regions in other wealthy countries.

\section{Conclusions}

Based on our results, we would like to conclude this paper by proposing five starting points for regional development management bodies, such as governmental and nongovernmental organizations, to promote SQoL in rural regions.

1. Given the importance of family, friends, and social relationships for SQoL, we propose that regional development actors strengthen social relationships, for example by offering more sports and cultural activities as well as leisure activities in nature. The latter could also function as awareness-raising programs.

2. Our results concerning nature and landscape suggest that by preserving the quality of nature and landscapes, regional development actors can simultaneously promote other components of SQoL, especially leisure and recreation, living, health and safety, as well as social relations and equality. This does not mean, however, that measures related to nature and landscapes should be the only priority. Our findings indicate that the majority of respondents considered all nine components to be important for SQoL.

3. Since some of the interview participants expressed views or described situations that are not compatible with equality, regional development actors could focus on raising awareness of equality issues and equal rights of minorities to promote SQoL.

4. The discrepancy between high levels of environmental concern and lower levels of actual pro-environmental behavior can be addressed by promoting infrastructures and social innovations that enable more ecological behavior. This includes widely accessible supply of renewable energies, targeted spatial planning, the expansion of public transport services along with more attractive pricing, and support of electric mobility and alternative mobility concepts such as car-sharing.

5. All of the above starting points are connected to knowledge, sensitization, innovative action, and the development of projects and measures of various kinds. Therefore, knowledge on sustainability-including a wide range of topics from green technologies to human rights-seems essential. We propose that regional development actors further expand environmental and sustainability education as a cross-cutting way of promoting SQoL. 
Supplementary Materials: Supplementary Information 1-5 is available online at https:/ /www. mdpi.com/article/10.3390/su13169187/s1.

Author Contributions: T.X.W., U.L., T.H. and R.B. contributed to the conception and design of the study. The first draft of the manuscript was written by T.X.W.; and T.X.W., U.L., T.H., R.B. commented on previous versions of the manuscript. All authors have read and agreed to the published version of the manuscript.

Funding: This study was financially supported by the Swiss National Science Foundation (SNSF, project 173372), for which we are very grateful.

Institutional Review Board Statement: At the university, where this study has been conducted, such research does not need specific ethical approval and we therefore did not seek ethic approval in this case. All required ethical standards are respected.

Informed Consent Statement: Informed consent was obtained from all subjects involved in the study.

Acknowledgments: Our sincere thanks go to Elena Siegrist for excellent research assistance. Furthermore, we thank Christine Scheidegger, Lea Jost, Christine Neff, and Florian Knaus for their support in the study regions. We gratefully acknowledge Michèle Amacker's comments on an early draft of the questionnaire.

Conflicts of Interest: The authors declare no conflict of interest.

\section{References}

1. OECD. How's Life? OECD: Paris, France, 2017.

2. Lin, D.; Hanscom, L.; Murthy, A.; Galli, A.; Evans, M.; Neill, E.; Mancini, M.S.; Martindill, J.; Medouar, F.-Z.; Huang, S. Ecological Footprint Accounting for Countries: Updates and Results of the National Footprint Accounts, 2012-2018. Resources 2018, 7, 58. [CrossRef]

3. O'Neill, D.; Fanning, A.L.; Lamb, W.F.; Steinberger, J.K. A Good Life for All within Planetary Boundaries. Nat. Sustain. 2018, 1, 88-95. [CrossRef]

4. Jorgenson, A.K. Economic Development and the Carbon Intensity of Human Well-Being. Nat. Clim. Chang. 2014, 4, 186-189. [CrossRef]

5. Verhofstadt, E.; Van Ootegem, L.; Defloor, B.; Bleys, B. Linking Individuals' Ecological Footprint to Their Subjective Well-Being. Ecol. Econ. 2016, 127, 80-89. [CrossRef]

6. Ambrey, C.L.; Daniels, P. Happiness and Footprints: Assessing the Relationship between Individual Well-Being and Carbon Footprints. Environ. Dev. Sustain. 2017, 19, 895-920. [CrossRef]

7. Boersema, J. Environmental Quality and the Quality of Our Way of Life. Environ. Values 1995, 4/2, 97-108. [CrossRef]

8. Collados, C.; Duane, T.P. Natural Capital and Quality of Life: A Model for Evaluating the Sustainability of Alternative Regional Development Paths. Ecol. Econ. 1999, 30, 441-460. [CrossRef]

9. Levett, R. Sustainability Indicators-Integrating Quality of Life and Environmental Protection. J. R. Stat. Soc. Ser. A Stat. Soc. 1998, 161, 291-302. [CrossRef]

10. Costanza, R.; Daly, L.; Fioramonti, L.; Giovannini, E.; Kubiszewski, I.; Mortensen, L.F.; Pickett, K.E.; Ragnarsdottir, K.V.; De Vogli, R.; Wilkinson, R. Modelling and Measuring Sustainable Wellbeing in Connection with the UN Sustainable Development Goals. Ecol. Econ. 2016, 130, 350-355. [CrossRef]

11. Distaso, A. Well-Being and/or Quality of Life in EU Countries through a Multidimensional Index of Sustainability. Ecol. Econ. 2007, 64, 163-180. [CrossRef]

12. Helliwell, J.F.; Layard, R.; Sachs, J. World Happiness Report. 2012. Available online: https://open.library.ubc.ca/soa/cIRcle/ collections/facultyresearchandpublications/52383/items/1.0053622 (accessed on 8 June 2020).

13. United Nations. Human Development Report 2016 Human Development for Everyone; United Nations Development Programme: New York, NY, USA, 2016; p. 286.

14. Swiss Federal Statistical Office. Indikatorensystem Wohlfahrtsmessung. Aktualisierte Version—Schaffung, Verteilung und Erhalt der Wohlfahrt; Swiss Federal Statistical Office: Neuchâtel, Switzerland, 2017.

15. Costanza, R.; Fisher, B.; Ali, S.; Beer, C.; Bond, L.; Boumans, R.; Danigelis, N.L.; Dickinson, J.; Elliott, C.; Farley, J.; et al. Quality of Life: An Approach Integrating Opportunities, Human Needs, and Subjective Well-Being. Ecol. Econ. 2007, 61, 267-276. [CrossRef]

16. Bakar, A.A.; Osman, M.M.; Bachok, S.; Ibrahim, M.; Mohamed, M.Z. Modelling Economic Wellbeing and Social Wellbeing for Sustainability: A Theoretical Concept. Procedia Environ. Sci. 2015, 28, 286-296. [CrossRef]

17. Acharyya, A. Groundwater, Climate Change and Sustainable Well Being of the Poor: Policy Options for South Asia, China and Africa. Procedia Soc. Behav. Sci. 2014, 157, 226-235. [CrossRef]

18. Astuti, L.T.M.; Tjiptoherijanto, P.; Haeruman, H.; Koestoer, R. Model of Sustainable Wellbeing on Decent House Study Case of Bekasi City, West Java, Indonesia. Procedia Environ. Sci. 2015, 28, 370-379. [CrossRef]

19. Helne, T.; Hirvilammi, T. Wellbeing and Sustainability: A Relational Approach. Sustain. Dev. 2015, 23, 167-175. [CrossRef] 
20. Higgins, P.; Campanera, J.M. (Sustainable) Quality of Life in English City Locations. Cities 2011, 28, 290-299. [CrossRef]

21. Holdren, J.P. Science and Technology for Sustainable Well-Being. Science 2008, 319, 424-434. [CrossRef]

22. ISTAT. Bes Report 2018: Equitable and Sustainable Well-Being in Italy; Instituto Nazionale di Statsitica: Rome, Italy, 2019.

23. Maack, M.; Davidsdottir, B. Five Capital Impact Assessment: Appraisal Framework Based on Theory of Sustainable Well-Being. Renew. Sustain. Energy Rev. 2015, 50, 1338-1351. [CrossRef]

24. Manelli, A. New Paradigms for a Sustainable Well-Being. Agric. Agric. Sci. Procedia 2016, 8, 617-627. [CrossRef]

25. Pachauri, R.K. Sustainable Well-Being. Science 2007, 315, 913. [CrossRef] [PubMed]

26. Kjell, O.N. Sustainable Well-Being: A Potential Synergy between Sustainability and Well-Being Research. Rev. Gen. Psychol. 2011, 15, 255-266. [CrossRef]

27. O'Brien, C. Sustainable Happiness: How Happiness Studies Can Contribute to a More Sustainable Future. Can. Psychol. 2008, 49, 289-295. [CrossRef]

28. Kobza, N. Engineering Sustainable Happiness. IFAC-Pap. 2015, 48, 195-200. [CrossRef]

29. Cloutier, S.; Pfeiffer, D. Sustainability Through Happiness: A Framework for Sustainable Development. Sustain. Dev. 2015, 23, 317-327. [CrossRef]

30. Rogers, D.S.; Duraiappah, A.K.; Antons, D.C.; Munoz, P.; Bai, X.; Fragkias, M.; Gutscher, H. A Vision for Human Well-Being: Transition to Social Sustainability. Environ. Sustain. 2012, 4, 61-73. [CrossRef]

31. Da Silva, J.M.C.; Li, H.; Barbosa, L.C.F. The Ecological Intensity of Human Well-Being at the Local Level. Environ. Sustain. Indic. 2020, 8, 100061. [CrossRef]

32. Kowaltowski, D.C.C.K.; da Silva, V.G.; Pina, S.A.M.G.; Labaki, L.C.; Ruschel, R.C.; de Carvalho Moreira, D. Quality of Life and Sustainability Issues as Seen by the Population of Low-Income Housing in the Region of Campinas, Brazil. Habitat Int. 2006, 30, 1100-1114. [CrossRef]

33. United Nations. The Sustainable Development Goals Report; United Nations: New York, NY, USA, 2019.

34. Brown, D.; Schucksmith, M.; Brown, D.L.; Schucksmith, M. A New Lens for Examining Rural Change. European Countryside. Eur. Countrys. 2016, 8, 83-188. [CrossRef]

35. Johansson, M.; Nilsson, P.; Westlund, H. Demographic and Economic Trends in Rural Europe. In Social Capital and Development Trends in Rural Areas; Centrum for Regional Science (CERUM): Umea, Sweden, 2015; Volume 10, pp. $129-157$.

36. Hennig, E.I.; Schwick, C.; Soukup, T.; Orlitová, E.; Kienast, F.; Jaeger, J.A.G. Multi-Scale Analysis of Urban Sprawl in Europe: Towards a European de-Sprawling Strategy. Land Use Policy 2015, 49, 483-498. [CrossRef]

37. Bryman, A.; Burgess, R. Qualitative Research; SAGE Publications Ltd: London, UK, 1999; ISBN 978-0-7619-6243-4.

38. Kuckartz, U. Qualitative Inhaltsanalyse. Methoden, Praxis, Computerunterstützung; Beltz Juventa: Weinheim, Germany, 2012.

39. Rawls, J. A Theory of Justice; Harvard University Press: Cambridge, MA, USA, 2009; ISBN 978-0-674-04258-2.

40. Schlosberg, D. Defining Environmental Justice: Theories, Movements, and Nature; Oxford University Press: Oxford, UK, 2009.

41. Nussbaum, M.; Sen, A. The Quality of Life; Oxford University Press: Oxford, UK, 1993.

42. Frey, B.S.; Stutzer, A. Happiness and Economics: How the Economy and Institutions Affect Human Well-Being; Princeton University Press: Princeton, NZ, USA, 2010.

43. Layard, R. Happiness: Lessons from a New Science, reprint ed.; Penguin Group: London, UK, 2006; ISBN 978-0-14-303701-9.

44. Weimann, J.; Knabe, A.; Schöb, R. Measuring Happiness: The Economics of Well-Being; MIT Press: Cambridge, MA, USA, 2015; ISBN 978-0-262-02844-8.

45. Oermann, N.O.; Weinert, A. Nachhaltigkeitsethik. In Nachhaltigkeit Wofür? Von Chancen und Herausforderungen für Eine Nachhaltige Zukunft; Zimmermann, F., Ed.; Springer: Berlin/Heidelberg, Germany, 2016; pp. 63-85.

46. Zimmermann, F.M. Nachhaltigkeit Wofür? Von Chancen und Herausforderungen für Eine Nachhaltige Zukunft; Springer: Berlin/Heidelberg, Germany, 2016; ISBN 978-3-662-48191-2.

47. Brundtland, G.H.; Khalid, M.; Agnelli, S.; Al-Athel, S.; Chidzero, B. Our Common Future; Cambridge University Press: Cambridge, UK, 1987.

48. Schneidewind, U. Einfacher Gut Leben: Suffizienz und Postwachstum. Polit. Ökol. 2017, 148, $98-103$.

49. Bentham, J.; Mill, J.S. Utilitarianism and Other Essays; Penguin: London, UK, 2004.

50. Waterman, A.S. The Best within Us: Positive Psychology Perspectives on Eudaimonia; American Psychological Association, Clark University: Worcester, MA, USA, 2013.

51. Noll, H.-H. Konzepte der Wohlfahrtsentwicklung: Lebensqualität und "Neue" Wohlfahrtskonzepte; WZB Discussion Paper; Wissenschaftszentrum Berlin für Sozialforschung WZB: Berlin, Germany, 2000.

52. Diener, E. Guidelines for National Indicators of Subjective Well-Being and Ill-Being. J. Happiness Stud. 2006, 7, 397-404. [CrossRef]

53. Barbier, E. The Policy Challenges for Green Economy and Sustainable Economic Development. In Natural Resources Forum; Wiley Online Library: Hoboken, NJ, USA, 2011; Volume 35, pp. 233-245.

54. Wackernagel, M.; Lin, D.; Evans, M.; Hanscom, L.; Raven, P. Defying the Footprint Oracle: Implications of Country Resource Trends. Sustainability 2019, 11, 2164. [CrossRef]

55. Preisendörfer, P. Umweltgerechtigkeit. Von Sozial-Räumlicher Ungleichheit Hin Zu Postulierter Ungerechtigkeit Lokaler Umweltbelastungen. SozW Soz. Welt 2014, 65, 25-45. [CrossRef]

56. Hayek, F.A. Grundsätze Einer Liberalen Gesellschaftsordnung; Viktor Vanberg: Tübingen, Germany, 2002 ; Volume 5.

57. Nozick, R. The Examined Life: Philosophical Meditations; Simon and Schuster: New York, NY, USA, 1990. 
58. Mill, J.S. Utilitarianism; Broadview Press: Peterborough, ON, Canada, 2016.

59. Nussbaum, M.C. Creating Capabilities. The Human Development Approach; Harvard University Press: Cambridge, MA, USA, 2011.

60. Nurse, K. Culture as the Fourth Pillar of Sustainable Development. Small States Econ. Rev. Basic Stat. 2006, 11, 28-40.

61. Abraham, A.; Sommerhalder, K.; Abel, T. Landscape and Well-Being: A Scoping Study on the Health-Promoting Impact of Outdoor Environments. Int. J. Public Health 2010, 55, 59-69. [CrossRef] [PubMed]

62. Bieling, C.; Plieninger, T.; Pirker, H.; Vogl, C.R. Linkages between Landscapes and Human Well-Being: An Empirical Exploration with Short Interviews. Ecol. Econ. 2014, 105, 19-30. [CrossRef]

63. Cooper Marcus, C. Therapeutic landscapes. In Environmental Psychology and Human Well-Being. Effects of Built and Natural Settings; Academic Press: Cambridge, MA, USA, 2018; pp. 387-413, ISBN 978-0-12-811481-0.

64. Lengen, C. Place Identity: Identitätskonstituierende Funktionen von Ort und Landschaft. In Landschaft, Identität und Gesundheit; Springer: Wiesbaden, Germany, 2016; pp. 185-199, ISBN 978-3-531-19722-7.

65. Mocior, E.; Kruse, M. Educational Values and Services of Ecosystems and Landscapes-An Overview. Ecol. Indic. 2016, 60, 137-151. [CrossRef]

66. Romagosa, F.; Eagles, P.F.J.; Lemieux, C.J. From the inside out to the Outside in: Exploring the Role of Parks and Protected Areas as Providers of Human Health and Well-Being. J. Outdoor Recreat. Tour. 2015, 10, 70-77. [CrossRef]

67. Swiss Academy of Science. Biodiversity, a Guarantee of Health? Swiss Acad. Fact Sheets 2019, 14, 1-10.

68. Sen, A. Capability and Well-Being. In The Quality of Life; Oxford University Press: Oxford, UK, 1993 ; pp. 62-66.

69. Kurt, H.; Wagner, B. Kultur-Kunst_Nachhaltigkeit. Die Bedeutung von Kultur Für Das Leitbild Nachhaltige Entwicklung; Klartext Verlag: Essen, Germany, 2001.

70. Meschik, M.; Meth, D. Öffentliches Verkehrsangebot in Ländlichen Räumen—Gestaltungsmöglichkeiten und Auswirkungen auf die Lebensqualität. Gaia 2008, 17, 42-49. [CrossRef]

71. Swiss Federal Office for Statistics Gemeindetypologie. 2012 Mit 9 Kategorien (Politische Gemeinden). Available online: https: //www.bfs.admin.ch/bfs/de/home/statistiken/querschnittsthemen/raeumliche-analysen.assetdetail.2543279.html (accessed on 8 June 2020).

72. Glaser, B.G.; Strauss, A.L. The Discovery of Grounded Theory. Strategies for Qualitative Research; Aldine Publishing Company: Chicago, IL, USA, 1967.

73. Breuer, F.; Muckel, P.; Dieris, B. Reflexive Grounded Theory: Eine Einführung für die Forschungspraxis; Springer: Wiesbaden, Germany, 2018; ISBN 978-3-658-15420-2.

74. Dresing, T.; Pehl, T. Praxisbuch Interview, Transkription \& Analyse: Anleitungen und Regelsysteme für Qualitativ Forschende, 6th ed.; Dr. Dresing und Pehl GmbH: Marburg, Germany, 2015; ISBN 978-3-8185-0489-2.

75. Mayring, P. Qualitative Content Analysis: Theoretical Foundation, Basic Procedures and Software Solution; SSOAR: Klagenfurt, Austria, 2014.

76. Fanning, A.L.; O'Neill, D.W. The Wellbeing-Consumption Paradox: Happiness, Health, Income, and Carbon Emissions in Growing versus Non-Growing Economies. J. Clean. Prod. 2019, 212, 810-821. [CrossRef]

77. Bignante, E. Therapeutic Landscapes of Traditional Healing: Building Spaces of Well-Being with the Traditional Healer in St. Louis, Senegal. Soc. Cult. Geogr. 2015, 16, 698-713. [CrossRef]

78. Egoz, S. Landscape as a Driver for Well-Being: The ELC in the Globalist Arena. Landsc. Res. 2011, 36, 509-534. [CrossRef]

79. Nussbaum, M. Political Emotions; Harvard University Press: Cambridge, MA, USA, 2013.

80. Ostrom, E. Governing the Commons: The Evolution of Institutions for Collective Action; Cambridge University Press: Cambridge, MA, USA, 1990.

81. Knight, K.W.; Rosa, E.A.; Schor, J.B. Could Working Less Reduce Pressures on the Environment? A Cross-National Panel Analysis of OECD Countries, 1970-2007. Glob. Environ. Chang. 2013, 23, 691-700. [CrossRef]

82. Global Footprint Network Global Footprint Network. Advancing the Science of Sustainability. Available online: http://data. footprintnetwork.org/\#/ (accessed on 8 November 2019).

83. Dao, H.; Peduzzi, P.; Chatenoux, B.; De Bono, A.; Schwarzer, S.; Friot, D. Environmental Limits and Swiss Footprints Based on Planetary Boundaries: A Study Commissioned by the Swiss Federal Office for the Environment; Swiss Federal Office for the Environment (FOEN): Geneva, Switzerland, 2015.

84. Mounce, R.; Beecroft, M.; Nelson, J.D. On the Role of Frameworks and Smart Mobility in Addressing the Rural Mobility Problem. Res. Transp. Econ. 2020, 100956. [CrossRef]

85. Mattioli, G.; Colleoni, M. Transport Disadvantage, Car Dependence and Urban Form. In Understanding Mobilities for Designing Contemporary Cities; Pucci, P., Colleoni, M., Eds.; Springer International Publishing: Cham, Switzerland, 2015; pp. 171-190, ISBN 978-3-319-22577-7. 